\title{
Improvement of tools for decision support systems (DSS) in corporate information systems of industrial enterprises
}

\author{
Andrey Plakhin ${ }^{1}$, Igor Semenets ${ }^{2}$, Ekaterina Ogorodnikova ${ }^{3}$ and Denis Mironov ${ }^{4 *}$ \\ ${ }^{1}$ Ural State University of Economics, Department of Management, 8th March str. 62, Ekaterinburg, \\ Russian Federation \\ ${ }^{2}$ Slavonic University of the Republic of Moldova, Department of Economics, Florilor str. 28/1, \\ Chisinau, Moldova \\ ${ }^{3}$ Ural State University of Economics, Department of Management, 8th March str. 62, Ekaterinburg, \\ Russian Federation \\ ${ }^{4}$ Ural State University of Economics, Department of Applied Mathematics, 8th March str. 62, \\ Ekaterinburg, Russian Federation
}

\begin{abstract}
Modern industrial enterprises require more qualitative and indepth approaches to the processing of accounting information and its subsequent use in operational activities. The study presents the research results of current situation over the problem that need to be solved by forming and improving the tools for decision support systems. According to the authors of the article, such a toolkit should be an integral part of the corporate information system along with other vital modules.
\end{abstract}

\section{Introduction}

The conditions of a rapidly changing economic environment necessitate a high quality management for industrial enterprises, which must be constantly improved and continuously developed.

The need for successful operation in a tight competitive environment dictates its requirements for the efficiency of the business processes of the enterprise. The solution of the problem of increasing efficiency is inextricably linked with the provision of information support processes, so today almost no one doubts the need to build an integrated information system of the enterprise. Experts believe that the issues of building an information system should be addressed in the context of the business processes improving. There is also a clear understanding that the most effective will be a system that provides continuous information support of the production cycle from the development of a new product to the release of finished products. Such an approach will allow solving the tasks of information integration of all business processes; to carry out cooperation, both between individual units of the enterprise, and between enterprises, including those located in different countries; use a variety of information of a functioning database for all product life cycle stages.

\footnotetext{
*Corresponding author: apla@,usue.ru
} 
The issues of creation, development and implementation of decision support systems in corporate information systems, as well as business analytics were considered in the works of such researchers as: D. Appelbaum, A. Kogan, M. Vasarhelyi [1]; S. Dezdar [2]; C.-K. Hou [3]; P. Ifinedo [4]; T. Kamps, R. Stenzel, L. Chen [5]; J.-D. Leu, L. J.-H. Lee [6]; B. Niu, K. Chen, H. Huang [7]; S. Oman, R. Leskovar, B. Rosi [8]; R. Rajnoha, J. Kadarova, A. Sujova [9]; A. Uçaktürk, M. Villard [10]; M.K. Zaini, M. N. Masrek, M. D. Sani [11], D. J. Power [17] and others.

The work [1] is of scientific interest, where the authors propose to use Managerial Accounting Data Analytics (MADA), based on the balanced scorecard (BSC) theory in a business intelligence context. It is assumed that MADA will be able to provide management accountants the ability to utilize comprehensive business analytics to conduct performance measurement and provide decision related information.

C.-K. Hou [3] in his studies, also draws attention to the capabilities of the BCS and develops a multidimensional measurement for assessing organizational performance, based on the balanced scorecard approach in order to improve the effectiveness of decisionmaking systems. Data for his study were collected from 139 companies in the semiconductor industry in Taiwan and the relationships proposed in the framework were tested using Partial Least Squares method. The results indicate that higher levels of business intelligence system usage will lead to improved financial performance indirectly through enhanced internal process, learning and growth and customer performance.

Authors of other studies in order to improve information systems offer different management tools, in particular value engineering methodology and Six Sigma tools [6], integration of manufacturing execution systems and ERP in supply chains [8], Strategic Knowledge Management [10], Information Security Management [11] etc. Nevertheless, in our opinion, the issues of conceptual modelling and algorithmization of decision-making for the launch of programs for the technical development of industrial corporations that take into account the dynamics of the external environment, as well as corporate and functional strategies of the enterprise are currently not yet sufficiently developed [12].

However, there is no doubt that a high quality of management can be achieved only as a result of the availability, use and effective processing of a significant amount of quantitative and qualitative information. Industrial enterprises are now ready to invest substantial funds in the development of corporate information systems that improve business productivity, expand the flexibility of the production program and ensure the high efficiency of controlling mechanisms that determine the profitability of the business, while taking into account market conditions and consumer requirements [13].

\section{Assessment of the overall situation and trends in the market of ERP systems}

In recent years, the active introduction of corporate information systems at Russian enterprises has made it possible to identify a number of major trends in this market, including:

- an increase in the degree of integration of Russian and foreign systems;

- high competition of Russian developers;

- increasing the number of developers and various low-cost enterprise solutions for small and medium-sized businesses;

- an active transition to the standards of a new generation - systems of the ERP class.

Modern corporate information systems of the ERP class represent integrated solutions based on the integration of practical all functional areas of the enterprise, including production, finance, marketing, human resources management and others [10]. Enterprise 
resource planning (ERP) systems are highly complex business information systems. The implementation of these systems requires a high cost, corporate time and resources [9].

As studies show, such integrated systems are in demand on the Russian market, which $\mathrm{IDC}^{\dagger}$ estimated in 2015 to be more than $\$ 1.5$ billion, which is $4.3 \%$ more than in the previous year. Analysts' opinions agree that this market will continue to grow at an annual rate of at least $3.5 \%$, with a special demand from production and trading companies, whose share currently exceeds $40 \%$ of the market as a whole.

IDC has been investigating the Russian market for ERP systems for a long time and notes that the market is very concentrated - in recent years, about half of the market is occupied by SAP, the share of $1 \mathrm{C}$ has quickly increased, taking interest from its competitors. Approximately by $2010,1 \mathrm{C}$ occupied a share of about a quarter of the market. By 2012, 1C took a strong 2nd position, but showed the lowest dynamics in comparison with the top five leaders. Currently, the cost share of SAP, according to TAdviser, is about $40.6 \%$ of the entire Russian market, $1 \mathrm{C}-27.4 \%$, Microsoft $-7.2 \%$, Borlas $-4.8 \%$, IBS $3.8 \%$, Oracle $-3.3 \%$, Maykor-GMCS $-3.0 \%$, Galaktika $-2.8 \%$. The total share of the listed companies is $92.9 \%$ of the market. Two suppliers - SAP and $1 \mathrm{C}$ control over $70 \%$ of the market (Figure 1) [16].

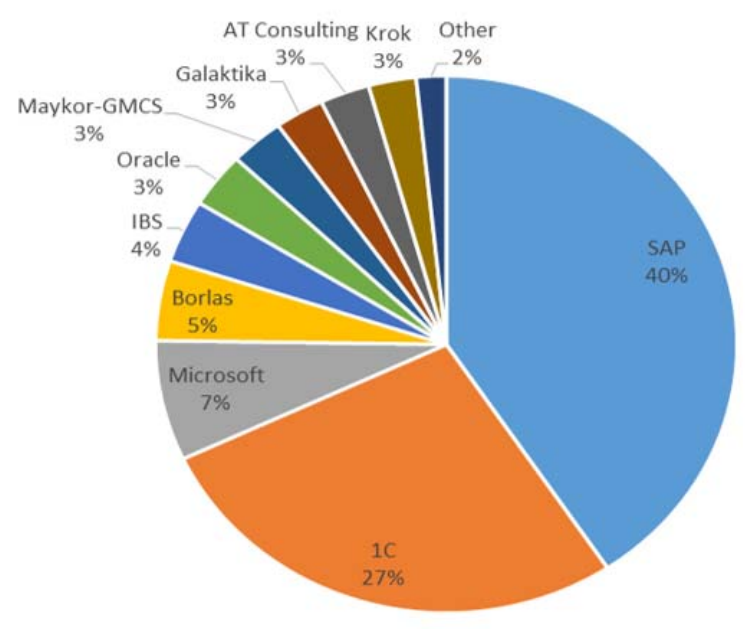

Fig. 1. Proportion of manufacturers of ERP-systems on the Russian market, 2017.

It is noteworthy that Yekaterinburg is among the leaders in the number of implemented projects for implementing ERP-systems. According to TAdviser, the total number of ERP projects in Russia is approaching 9,000, of which only 190 projects have been implemented in Yekaterinburg. However, the capital of the Middle Urals is much inferior to Moscow and St. Petersburg, where in total more than 6000 projects were realized.

In the first ten sectors of the volume of ERP-implementation in Russia, according to TAdviser, includes engineering, construction, food and chemical industry, financial services, housing and communal services and household services, pharmaceuticals and medicine, metallurgy and electricity. If we calculate the share of all industrial sectors in the top ten in aggregate, then they will have more than 2 thousand projects or about $35 \%$ of the total number of projects in the TAdviser database. In the structural plan of the industry

\footnotetext{
$\dagger^{\dagger} \mathrm{http}: / /$ idcrussia.com

$\$$ Tadviser - November 2017: http://www.tadviser.ru/index.php/ERP
} 
leaders in terms of the number of ERP-implementations, there were almost 1,400 trade projects, which amounted to $15.9 \%$ of the total number (Figure 2) [16].

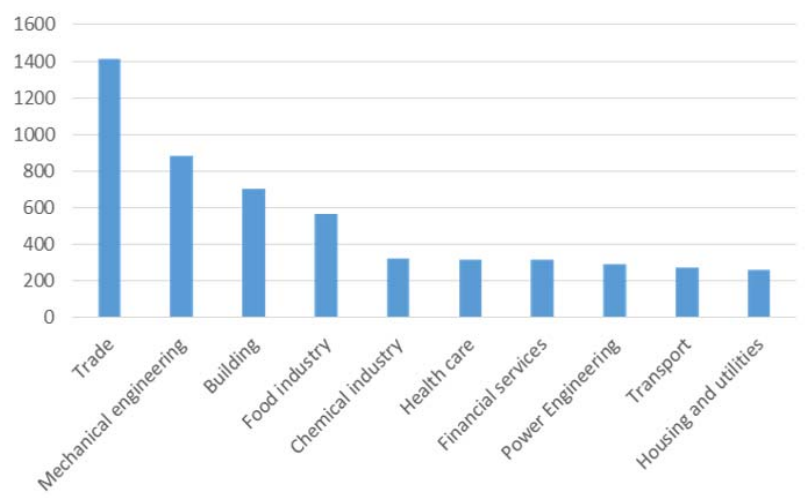

Fig. 2. Top-10 industries by the number of ERP projects $\$$.

It is important to note that in addition to effective monitoring of business processes on the basis of a single ERP-system platform, first of all, they ensure compatibility in gathering information from the whole enterprise, further processing, and implementation of such management functions as analysis, planning and control.

On the other hand, these systems play a significant role in increasing the effectiveness of management decisions, being the main source of information necessary for the development of management alternatives and choosing the most rational variant of actions for certain technical and economic parameters [14].

Due to their functionality, ERP-systems are the most preferable in the process of making managerial decisions, since the decision maker has the ability to quickly access information collected from all levels of management to solve a particular situation or problem.

\section{The problem of improving the ERP systems}

The tasks of managing a modern enterprise are significantly complicated in a dynamic external environment, and therefore, it is obvious that an additional ERP system setup is required to integrate Decision Support System (DSS) in its functionality. Typically, the DSS subsystem is isolated from the main production information systems and uses their data and information flows for the operation of their analytical systems. In our opinion, the classical structure of the ERP-system can be supplemented by adding a block of support for making managerial decisions (Figure 3).

Traditionally, ERP-systems are built on the basis of a three-tier client-server architecture, when an application server is located between the database server and clients, is responsible for implementing the entire business logic of the system. The procedure for implementing the ERP-system includes the creation of working group on the introduction of IP, the identification of information flows in the enterprise, the formation of a regulatory and reference database of documents, the construction of conceptual, logical and physical models of enterprise activities, a description of optimization of business processes of the enterprise, the implementation of the pilot project, preliminary introduction.

$\S$ Tadviser - November 2017: http://www.tadviser.ru/index.php/ERP 
Organizational improvement of the management system, as well as its subsystems and various elements, will require corresponding changes not only in individual ties, but also in the management structure as a whole, which may include the introduction of new links, changes in individual management functions and, ultimately, ways of making managerial decisions [15].

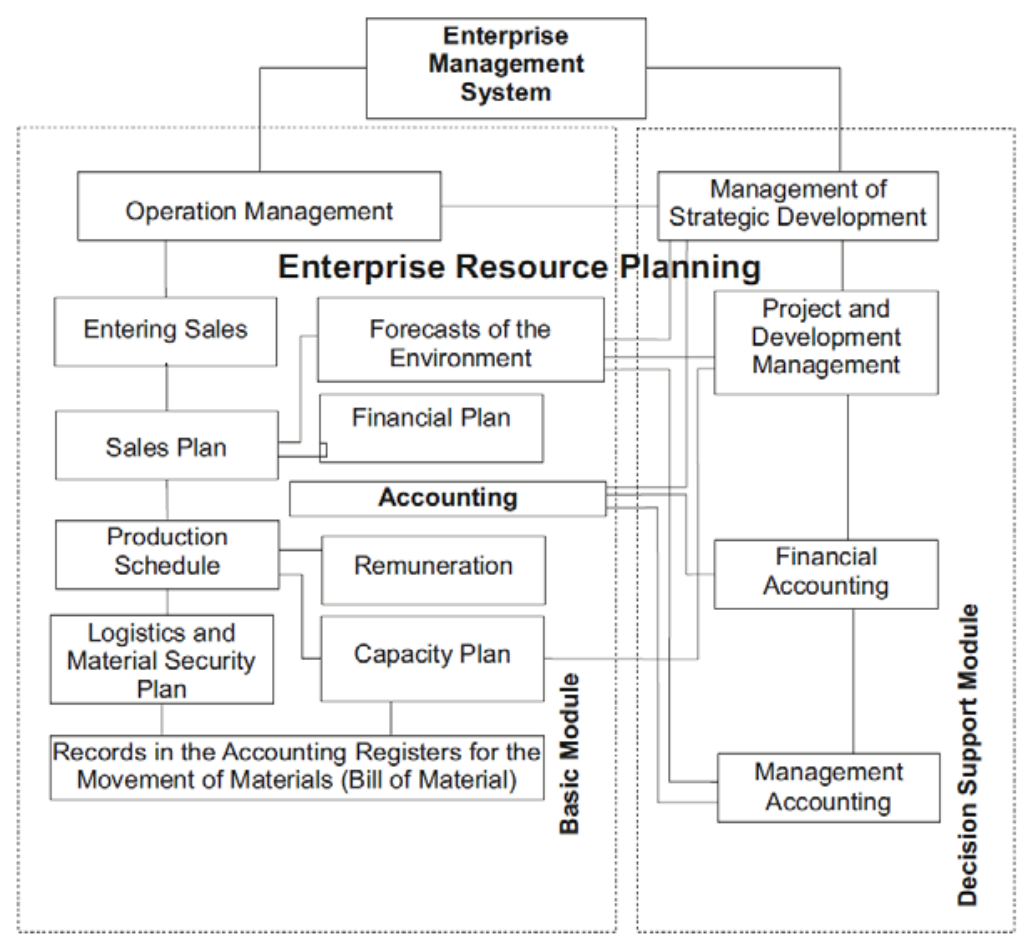

Fig.3. Structure of ERP-system with built-in decision support module.

In order to ensure sustainable development, industrial enterprises require the introduction of intelligent technologies for managing changes in a highly competitive environment. Modern software tools that exist separately from ERP-systems are already able to solve complex tasks of making managerial decisions by building mathematical dependencies and finding optimal planning results.

\section{Discussion and directions of further research}

The tasks of linear and non-linear programming can be solved by means of MS Excel and other similar software products, but they are left without due attention in our opinion in corporate information systems. In addition, managers at different levels, as well as management accounting specialists, economists-analysts, often need to evaluate performance by calculating the criteria PP, DPP, NPV, IRR, IP** of various development projects, organizational and technical measures, but integrated into the corporate information system such opportunities is also not found. In this case, to acquire specialized

\footnotetext{
${ }^{* * *}$ PP - payback period, DPP - discounted payback period, NPV - net present value, IRR - internal rate of return, IP - index of profitability.
} 
software products of the enterprise does not hurry up, but leave the solution of these tasks to the same MS Excel.

The integrated information system in addition to providing the ability to quickly collect, store and analyze data requires high discipline on the part of the employees of the enterprise and ensures the construction of a clear structure and sequence of business processes. In the organization of vertical and horizontal interaction of the divisions of an industrial enterprise in the production of products the information system becomes a key aspect of increasing competitiveness. Thanks to the completion of the ERP-system by means of DSS, there will be a significant effect in reducing the time spent by managers and specialists on the search for optimal management decisions. In this case, we can talk about the conformity of the management system of an industrial company with the requirements of the present.

Increase of competitiveness of the enterprise at use of the integrated information system of maintenance of acceptance of administrative decisions is reached due to:

- full consideration of available information in the design and adoption of management decisions because decision-makers have online access to the databases of all automated systems and, therefore, can optimize work plans, content of applications, distribution of executors, allocation of finance, etc .;

- Reduction of material and time costs for the design and manufacture of the product since the description of previously completed successful developments will be stored in databases;

- Reduction of operating costs through the implementation of integrated information support functions.

In our opinion, a special interest for further research can be the study of the experience of implementing business intelligence technologies in the tasks of optimizing and improving the business processes of companies, as well as implementing project management tools.

\section{References}

1. D. Appelbaum, A. Kogan, M. Vasarhelyi, Int. J. Acc. Inf. Sys. 25, 29 (2017)

2. S. Dezdar, Int. J. IT Pr. Man. 8 (3), 52 (2017)

3. C.-K. Hou, Inf. Dev. 32 (5), 1545 (2016)

4. P. Ifinedo, J. Comp. Inf. Sys. 47 (4), 28 (2016)

5. T. Kamps, R. Stenzel, L. Chen, (Essays dedicated to Erich J. Neuhold on the occasion of his 65th birthday), 3379, 271 (2005)

6. J.-D. Leu, L.J.-H. Lee, Ent. Inf. Sys. 11 (8), 1243 (2017)

7. B. Niu, K. Chen, H. Huang, Int. J. Comp. Comm. \& Cont. 12 (3), 347 (2017)

8. S. Oman, R. Leskovar, B. Rosi, Tehn. Ves. 24 (6), 1889 (2017)

9. R. Rajnoha, J. Kadarova, A. Sujova, BEM 109, 165 (2013)

10. A. Uçaktürk, M. Villard, Pr.Soc. Beh. Sc. 99, 1035 (2013)

11. M.K. Zaini, M.N. Masrek, M.D. Sani, IBIMAC I-VII, 2255 (2017)

12. J. Weber, I. Srpova et al. Corporate Management: Problems of Internal and External Integration (USUE, Ekaterinburg, 2003)

13. O.V. Pergunova, Pros. Dev. IT 143, 87 (2013)

14. S.A. Gusev, Zh.A. Zolotushkina, Log. Sys. Glob. Ec. 5, 183 (2015)

15. N.R. Kovalev, A.E. Plakhin, Investigation of management systems, (USUE, Ekaterinburg, 2006) 
16. Tadviser, http://www.tadviser.ru/index.php/ERP (2017)

17. D.J. Power, http://DSSResources.COM/history/dsshistory.html (2007) 